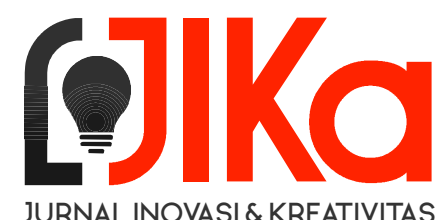

JURNAL INOVASI \& KREATIVITAS
JURNAL INOVASI DAN KREATIVITAS (JIKa)

Volume 1 Nomor 1 2021; p-ISSN 2776-1843

Doi: dx.doi.org/10.30656/JIKa.v1i1.3282

https://e-jurnal.Ippmunsera.org/index.php/JIKa

SK No. 0005.27761843/K.4/SK.ISSN/2021

\title{
PENINGKATAN KEANDALAN LOAD LUGGER DENGAN PENDEKATAN FAILURE MODE AND EFFECT ANALYSIS
}

\section{IMPROVING LOAD LUGGER RELIABILITY WITH FAILURE MODE AND EFFECT ANALYSIS APPROACH}

\author{
Fitriah, Heri Setiawan, Ahmad Nalhadi, Eko Hadi Sucipto, Supriyadi \\ Program Studi Teknik Industri, Fakultas Teknik, Universitas Serang Raya \\ fitriah582@gmail.com, herisetiawan2209@gmail.com, irqi02@gmail.com, \\ supriyadi@unsera.ac.id
}

Program Studi Teknik Industri, Fakultas Teknik, Sekolah Tinggi Teknologi Mutu Muhammadiyah Tangerang eko_hadisucipto@yahoo.com

\section{Abstract}

Problems: The reliability of equipment is one of the factors to increase work productivity. The high downtime rate on the load-lugger machine creates job delays that impact equipment performance.

Purpose: To determine the level of load-lugger availability and improve the downtime level to increase the availability of the load-lugger.

Methodology: This study uses the Failure Mode and Effect Analysis (FMEA) method to determine the process that causes the greatest downtime.

Results/Findings: Improvements by modifying the pin hook design and changing the pin hook material to make it more robust to withstand the weight of the scrap box and increasing the lifetime of the pin hook can increase the availability value from $74 \%$ to $99 \%$. The implementation of FMEA effectively identifies the level of damage to equipment as a basis for making repairs.

Paper Type: field research

Keywords: Availability; Equipment; FMEA; Load-lugger 


\section{Abstrak}

Masalah: Keandalan peralatan merupakan salah faktor untuk meningkatkan produktivitas kerja. Tingkat downtime yang tinggi pada mesin load lugger membuat delay pekerjaan yang berdampak pada kinerja peralatan

Tujuan: mengetahui tingkat availability load lugger dan perbaikan terhadap tingkat downtime untuk meningkatkan availability load lugger.

Metodologi: penelitian ini menggunakan metode Failure Mode and Effect Analysis (FMEA) untuk mengetahui proses yang menyebabkan downtime terbesar.

Temuan/Hasil Penelitian: Perbaikan dengan cara memodifikasi desain pin hook serta mengganti material pin hook agar lebih kuat menahan beban scrap box dan meningkatkan lifetime pin hook dapat meningkatkan nilai availability dari 74\% menjadi 99\%. Implementasi FMEA efektif dalam mengidentifikasi tingkat kerusakan suatu peralatan sebagai dasar melakukan perbaikan.

Jenis penelitian: Riset lapangan

Kata kunci: Availability; Peralatan; FMEA; Load Lugger

\section{A. PENDAHULUAN}

Kehandalan mesin merupakan salah satu faktor dalam menjaga kualitas dan produktivitas. Keandalan mesin memerlukan sistem perawat $\neg$ an yang baik diperlukan untuk men-dukung kinerja per $\neg$ alatan. Manajemen perawatan memาวpunyai fungsi mem-buat kebijakan terkait dengan memper $\neg$ baiki kerusakan fungsi operasional dengan meningkat $\neg$ kan umur pakai (Parinduri et al., 2018; Supriyadi et al., 2019), mengurangi kemung $\urcorner$ kinan ke $\neg$ rusak $\urcorner$ an dan downtime (Ardyanto and Felecia, 2015).

Load Lugger (LUG) merupakan sebuah kendaraan yang digunakan oleh sebuah perusahaan jasa logistik di daerah Cilegon. Selama periode bulan Januari sampai Juli 2019 sebesar 357 jam dengan 141 kejadian. Besarnya jam hilang yang disebabkan peralatan tidak beroperasi sangat berdampak pada kinerja peralatan yang secara tidak langsung akan mempengaruhi kinerja perusahaan.
Salah satu metode yang dapat digunakan untuk menganalisa kegagal $\neg$ an peralatan adalah Failure Mode and Effect Analysis (FMEA). FMEA sering digunakan untuk mendeteksi mode kegagalan sistem yang kompleks dalam meminimalkan faktor risiko dan meningkatkan keandalan peralatan (Mohsen and Fereshteh, 2017). Metode ini memerlukan pengalaman para ahli untuk menentukan mode kegagalan utama dan mendeteksi faktor paling kritis untuk mencegah risiko (Lo et al., 2019). FMEA membuat rangking ber $\neg$ dasar $\neg$ kan nilai RPN untuk memu $\neg$ dah $\neg$ kan prioritas perbaikan dari mode kegagal $\neg$ an (Supriyadi and Nabilla, 2020).

Implementasi FMEA membantu perusahaan dalam mengidentifikasi dan membuat kebijakan perbaikan sesuai dengan tingkat risiko kegagalan yang terjadi. Memodifikasi langkah kerja gripper bar dengan membuat pem $\neg$ batas agar tidak melebihi sudut 90o mampu mengatasi kegagalan jamming pada mesin Mandrel Tension Reel yang mempunyai nilai RPN terbesar (Reza et al., 2017). Implementasi 
metode FMEA pada mesin insulating mampu menu $\neg$ run $\neg$ kan tingkat kecacatan dari $3,22 \%$ menjadi $0,91 \%$ dengan cara mem $\neg$ fokuskan perbaikan pada insulation bocor dan kawat putus yang mem $\neg$ punyai nilai RPN tertinggi (Rochmoeljati, 2008).

Penelitian ini bertujuan menge-tahui nilai availability mesin Load Lugger sebagai dasar kebijakan per-baik $\neg a n$. Langkah perbaikan dengan meng $\urcorner g u n a\urcorner k a n$ diharapkan mampu meng $\neg$ atasi ke $\neg$ gagalan yang terjadi dan meningkatkan nilai availability. Pening-katan ini akan berdampak pada pening $\neg$ kat $\urcorner$ an produk $\neg$ tivitas mesin Load Lugger.

\section{B. KERANGKA TEORI}

Maintenance adalah semua tindak $\neg a n$ yang sesuai untuk memper-tahankan bagian/peralatan atau mengem $\neg$ balikannya ke kondisi tertentu. Tujuan utama pemeliharaan adalah untuk memastikan fungsi sistem (keter $\urcorner$ sediaan, efisiensi dan kualitas produk), umur sistem (manajemen aset) dan keamanan sistem dengan konsumsi energi yang rendah (Velmurugan and Dhingra, 2015). Pemeliharaan juga berfungsi untuk mengurangi tingkat kerugian yang diakibatkan kerusakan peralatan dan meningkatkan kinerja serta keter-sediaan dengan biaya yang efisien (Simeu-Abazi and Sassine, 2001).

Manajemen Perawatan Industri merupakan suatu sistem pemelihara $\neg a n$ fasilitas industri untuk mengatur aktivitas peralatan agar dapat menjaga proses produksi dalam menghasilkan produk yang berkualitas. Faktor penentu keberhasilan strategi pemeli-haᄀraan antara lain personel pemeliha-raan memiliki pengetahuan untuk mencegah kegagalan pada tahap awal, keterampilan manajemen ter $\neg$ masuk perencanaan, manajemen sumber daya manusia dan manajemen tugas, untuk memanfaat $\neg k a n$ tren dan peluang riwayat pemeliharaan (Velmurugan and Dhingra, 2015).
FMEA adalah metode analisis keandalıan yang sistematis dan preventif (Luko, 2013) untuk menganalisis mode kegagalan potensial dan penye-bab kegagalan serta dampak yang dihasil $\neg$ kan pada kinerja sistem (Zhou et al., 2016) untuk menentukan kebijakan penanganan lebih lanjut (Hasrul et al., 2017). FMEA meng-gunakan tiga parameter yang biasanya dievaluasi melalui ekspresi linguistik yang mudah ditafsirkan (1 - 10) yaitu Severity (S), Occurrence (O), dan Detection (D) (Wang et al., 2012). Severity mengukur keseriusan efek mode kegagalan. Occurrence terkait dengan kemungkinan terjadinya mode kegagalan. Detection menunjukkan visibilitas kegagalan yang merupakan sikap mode kegagalan untuk diiden-tifikasi oleh kontrol dan inspeksi. Risk Priority Number (RPN) diperoleh dari hasil ketiga parameter tersebut yang digunakan untuk mengukur risiko dan tingkat keparahan mode kegagalan.

\section{METODE PENELITIAN}

Objek penelitian ini pada unit load lugger (LUG) di salah satu perusahaan yang bergerak di bidang logistik service. Data yang diambil adalah data kerusakan selama 6 bulan dari bulan Januari 2019 hingga Juni 2019. Data awal diolah menggunakan perhitungan performance maintenance untuk mengetahui performance Load Lugger saat ini.

$$
\begin{aligned}
& M T B F=\frac{\text { Total Operation Time }}{\text { Frekuensi Breakdown }} \\
& M T T R=\frac{\text { Breakdown Time }}{\text { Frekuensi Breakdown }} \\
& \text { Availability }=\frac{\text { Total operation Time }}{\text { Loading Time }} \times \\
& 100 \%
\end{aligned}
$$

Identifikasi kegagalan unit load lugger menggunakan pendekatan FMEA. FMEA adalah alat keandalan yang banyak digunakan untuk meng-identifikasi potensi kegagalan sebelum terjadi dengan tujuan meminimalkan risiko yang terjadi (Chen, 2013). Fungsi dasar FMEA adalah menemukan, memprioritaskan, dan memini $\neg$ mal- 
kan kegagalan, terutama dalam industri manufaktur yang berkaitan dengan permasalahan keandalan per-alat $\neg$ an (Geum et al., 2011).

Langkah FMEA dalam penelitian ini adalah (1) melakukan review proses pada kegiatan loading scrap box; (2) membuat daftar pe $n$ nyebab dan efek potensial yang ditimbulkan; (3) menentukan nilai severity, occurrence dan detection; (4) menghitung nilai Risk Priority Number (RPN); (5) melakukan analisa dan perbaikan berdasarkan rangking dari nilai RPN dengan bantuan diagram fishbone.

RPN $=$ Severity $\times$ Occurance $\times$ Detection

\section{HASIL DAN PEMBAHASAN}

Selama periode Januari 2019-Juli 2019 load lugger mengalami downtime selama 141 kali dengan kehilangan waktu operasi sebesar 357 jam (Tabel 1). 3 jenis kerusakan dominan pada unit load lugger diantaranya yaitu kerusak $\urcorner$ an pada pin hook, ban dan hose jack hidrolic. Kerusakan paling sering terjadi yaitu kerusakan pin hook sebanyak 60 kejadian dan menyebab-kan delay selama 60 jam dengan persentase se $\neg$ besar 52,2\%, pergantian ban se $\neg$ banyak 35 kejadian dan menyebabkan delay selama 70 jam dengan persentase sebesar 30,4\% serta kerusakan pada hose jack hidrolic sebanyak 20 kejadian dan menyebab-kan delay selama 20 jam dengan persentase sebesar 17,4\%.

Penelitian ini tidak membahas kerusakาan ban meskipun ban memiliki delay terlama yaitu 70 jam karena jika ban rusak maka perbaikan yang dapat dilakukan yaitu hanya pergantian ban (run to failure).
Tabel 1

Data Breakdown Load Lugger

\begin{tabular}{clc}
\hline No & \multicolumn{1}{c}{ Bulan } & Breakdown (Jam) \\
\hline 1. & Januari & 111,6 \\
2. & Februari & 65,3 \\
3. & Maret & 43,8 \\
4. & April & 80,1 \\
5. & Mei & 10,2 \\
6. & Juni & 46,7 \\
\hline
\end{tabular}

Selama periode 6 bulan nilai availability load lugger adalah sebesar 78\% (Tabel 2). Nilai ini masih jauh dari standar global adalah 90\%. Nilai availability adalah rasio performance peralatan yang dipengaruhi oleh faktor downtime (Anthony, 2018). Rendahnya nilai ini berdampak kerugian bagi perusahaan karena peralatan tidak bisa bekerja secara maksimal. Nilai MTBF sebesar 5,8 jam mempunyai pengertian waktu rata-rata antara breakdown dengan breakdown berikutnya sebelum per-baik $\urcorner$ an adalah 5,8 jam. Nilai MTTR sebesar 1,3 jam menunjukkan waktu rata-rata yang digunakan oleh mekanik untuk memperbaiki kerusakan pada komponen load lugger.

Tabel 2

Rekapitulasi Performance Load Lugger

\begin{tabular}{cccc}
\hline Mesin & $\begin{array}{c}\text { MTTR } \\
\text { (jam) }\end{array}$ & $\begin{array}{c}\text { MTBF } \\
\text { (jam) }\end{array}$ & Avaibility \\
\hline $\begin{array}{c}\text { Load } \\
\text { Lugger }\end{array}$ & 1,3 & 5,8 & $78 \%$ \\
\hline
\end{tabular}

Load Lugger pada perusahaan digunakan untuk proses proses loading scrap box. Berdasarkan hasil pengamat $\neg$ an dan wawancara didapatkan jenis kegagalan pada proses loading scrap box yaitu pada proses finger point ada beberapa item pengecekan ter $\neg$ lewat, posisi mobil tidak sejajar dengan srap box pada saat proses mensejajarkan mobil dengan scrap box; tombol PTO tidak menyala pada saat menyalakan tombol power take off karena sekring putus; silinder lifting arm macet saat menurun $\neg$ kan lifting arm; posisi hook 
tidak pas dengan kupingan scrap box pada pemasangan hook; piston macet saat menurunkan hydraulic jack; pada proses menaikkan scrap box pada lantai kabin, posisi scrap box tidak sejajar dengan lantai kabin dan pin hook tidak kuat menahan beban pada scrap box; ketika menaikkan hydraulic jack, piston macet dan ketika akan mematikan tombol PTO, tombol PTO tidak menyala disebabkan sekring putus.

Tabel 3

Failure Mode and Effect Analysis

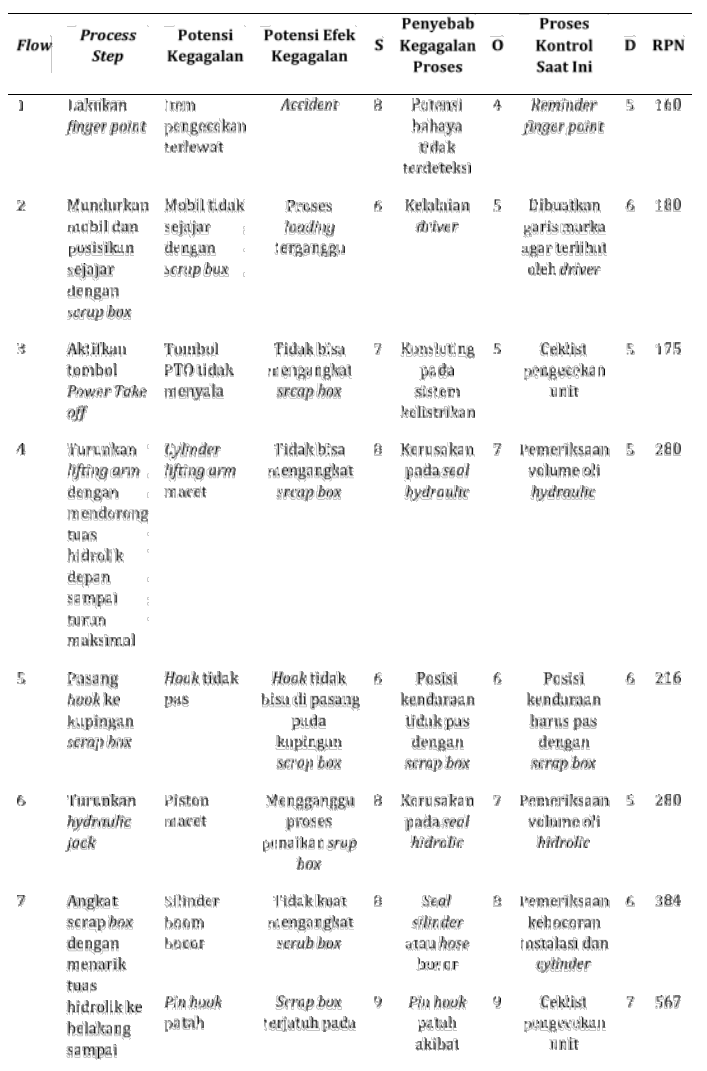

Potensi Kegagalan Loading Scrap Box telah didapatkan jenis kegagalan pada setiap proses loading. Analisis penyebab kegagalan yang terjadi menggunakan Failure Mode and Effect Analysis (FMEA). Analisis ini bertujuan untuk melihat dan mengetahui proses bagian mana yang lebih potensial terjadinya kegagalan pada proses loading scrap box.

Pembuatan Tabel FMEA dilaku-kan untuk menentukan jenis kegagalan dan menentukan efek dari kegagalan ter $\neg$ sebut dan selanjutnya men $\neg$ cari penyebab akibat kegagalan ter $\urcorner$ sebut. Penentuan kontrol akan dilakukan beserta upaya penanggulangannya. Jika sudah didapatkan jenis kegagalan, penyebab kegagalan, kontrol yang akan dilakukan serta upaya penanggulangan kegagalan tersebut maka dilakukan perhitungan nilai Risk Priority Number (RPN) yang diperoleh dari hasil perkalian antara nilai Severity, Occurrence dan Detection (Tabel 3).

Nilai RPN terbesar diperoleh pada proses pengangkatan scrap box pada lantai kabin dengan nilai RPN sebesar 567 dimana kegagalan potensial yang terjadi yaitu pin hook patah karena tidak kuat menahan scrap box sehingga jika proses tersebut tidak dapat dilanjut $\neg$ kan dan unit harus kembali ke workshop untuk dilakukan perbaikan atau penggantian pin hook. Nilai RPN ini merupakan nilai RPN tertinggi sehingga menjadi prioritas utama untuk dilaku $\neg$ kan perbaikan.

Untuk mengidentifikasi akar penyebab dari permasalahan pada pin hook menggunakan Fishbone Diagram. Faktor material menjadi salah satu penyebab dominan terjadi $\neg$ nya kerusak $\neg$ an pada pin hook karena pin berbentuk bulat sehingga pin tidak kuat menahan beban dan shock load mengakibatkan pin mudah patah dan diameter dalam rantai kecil sehingga diameter pin hook pun kecil dan mengakibatkan pin kurang kuat. Faktor manusia adalah operator atau driver yang mengoperasi $\neg$ kan lifting arm kasar sehingga terjadi benturan antara lifting arm dan scrap box. Faktor metode adalah operator yang sedang melakukan proses loading scrap box, cara pengoperasian lifting arm tidak sesuai SOP sehingga menyebab $\neg$ kan dalam mengoperasikan lifting arm kurang aman dan dapat menyebabkan accident.

Penyebab dominan pin hook rusak dan patah yaitu pin berbentuk bulat, tidak mengikuti bentuk rantai serta ukuran pin yang kecil dan material pin kurang keras. Hal tersebut dapat diperbaiki dengan cara 
mendesain ulang pin hook dan mengganti material pin hook yang bertujuan agar pin hook tahan terhadap beban yang ditopang sehingga tidak mudah rusak dan patah sehingga memperpanjang masa life time pin hook. Proses pembuatan dilakukan di workshop dikerjakan oleh para mekanik pada bulan September 2019.

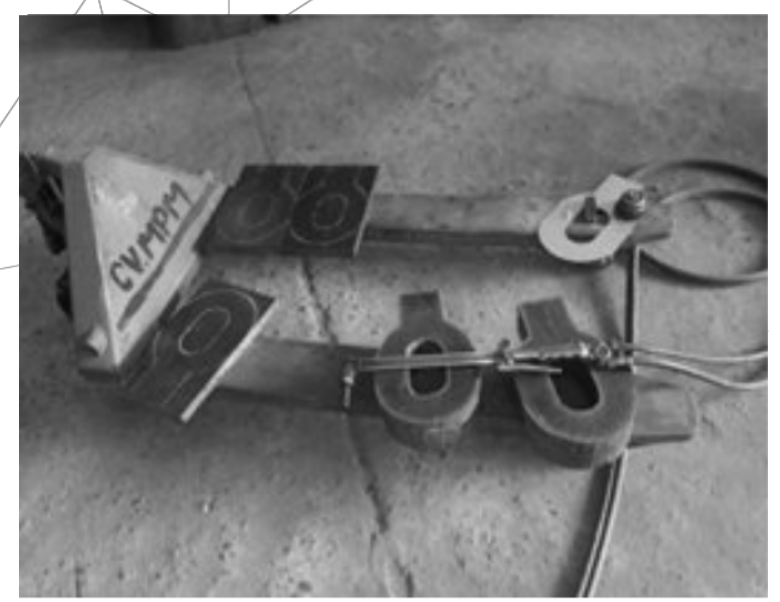

Gambar 1 Pin Hook Sebelum Modifikasi

Pin Hook sebelum modifikasi terlihat bahwa bentuk pin bulat, kecil dan tebal. Pin hook memiliki ukuran diameter $18 \mathrm{~mm}$ serta material pin hook yang digunakan sebelum modifikasi yaitu baja S45C (carbon steel) yang memiliki kandungan Carbon $0,42 \%$ sehingga material ini memiliki struktur yang keras dan getas menyebabkan pin hook mudah patah (Gambar 1).

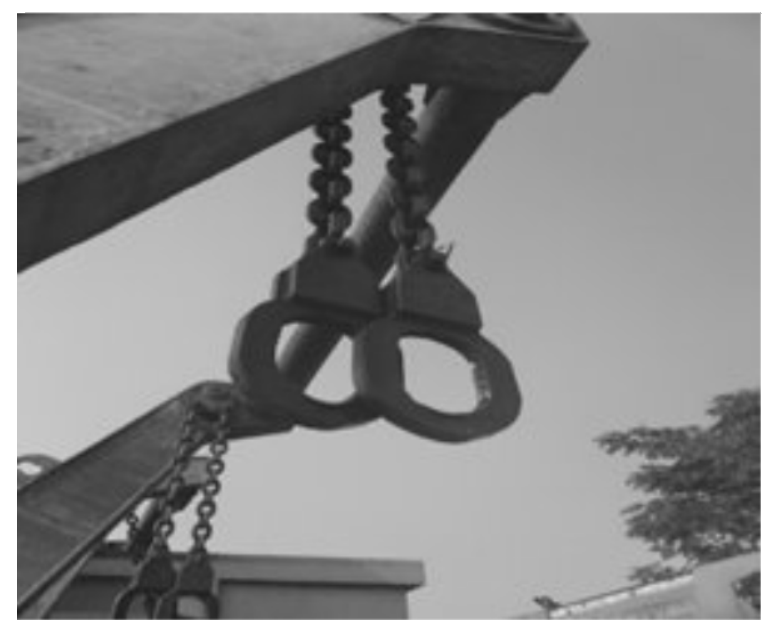

Gambar 2 Pin Hook Setelah Modifikasi

Pin Hook hasil modifikasi terlihat bahwa bentuk pin lebih besar dengan ukuran diameter $18 \mathrm{~mm}$ dan panjang $25 \mathrm{~mm}$ serta tidak terlalu tebal (Gambar 2). Material pin hook yang digunakan setelah dimodifikasi yaitu menggunakan material jenis baja VCN 150 (AISI 4340 Alloy Steel) dengan kandungan Carbon 0,38\% yang memiliki sifat lentur, lebih tahan terhadap gesekan dan tahan panas dibanding dengan baja jenis S45C. VCN 150 memiliki kandungan Chrome (Cr) 0,70\% sehingga baja menjadi sangat keras dan tahan aus. Adanya kandungan Molibdenum (Mo) ber-tujuan untuk meningkatkan kekuatan dan batas mulur baja terutama terhadap pembebanan yang kontinu serta menaikkan temperatur tempering. Penggunaan material jenis VCN150 sangat efektif karena pin hook menjadi lebih kuat terhadap pembeban $\urcorner$ an yang kontinu serta lifetime pin hook menjadi lebih lama.

Perbaikan peralatan me $\neg$ rupa $\neg$ kan salah satu langkah yang efektif untuk meningkatkan kinerja peralatan. Penambahan bantalan karet pada bagian bracket pengunci battery dapat meminimalkan longgarnya terminal battery pada unit Off-highway Truck (Putra et al., 2018). Modifikasi mesin TMC Segmen CBE 1160 dengan cara menambahkan fitur pembatas gerakan membuat mesin menjadi aman dan mampu mengurangi tingkat defect pada proses selanjutnya (Christi and Yuliawati, 2020).

Modifikasi pin hook lifting arm tahan terhadap beban dan jumlah kerusakan berkurang menjadi 3 kali dalam 6 bulan. Setelah dilakukan modifikasi pada pin hook selain berkurangnya frekuensi kerusakan tetapi juga nilai Availability pin hook meningkat menjadi 99\%, nilai MTBF sebelumnya 4,73 Jam menjadi 222,33 Jam serta nilai MTTR sebelumnya 1,25 Jam menjadi 1 Jam. Dalam peng-operasian pun lebih aman dan nyaman serta customer tidak komplain karena puas terhadap pelayanan yang diberi-kan. Hal ini dapat meningkatkan kepercaya $\neg$ an customer dan akan ber-dampak pada kerjasama antar dua perusahaan yang sudah berjalan. 
Hasil ini sesuai dengan penelitian proses pembuatan kaca cermin yang menunjukkan peningkatan nilai availability dari $60 \%$ menjadi $76 \%$ dari implementasi metode FMEA (Al Rasyid, 2018). Keefektifan FMEA didasarkan analisa kegagalan setiap proses hingga mendapatkan rangking prioritas per $\neg$ baikan. Rangking ini membuat pihak manajemen lebih fokus dalam mem $\neg$ buat kebijakan dalam penentuan prioritas perbaikan.

\section{KESIMPULAN}

Nilai availability awal load lugger seperti pin hook, ban dan hose jack hidrolic adalah 74\% dengan nilai Mean Time Between Failure (MTBF) sebesar 4,73 Jam dan nilai Mean Time To Repair (MTTR) sebesar 1,25 Jam. Perbaikan untuk meminimalkan kerusakan pin hook dilakukan dengan cara memodi-fikasi desain pin hook serta mengganti material pin hook agar lebih kuat menahan beban scrap box dan life time pin hook lebih tahan lama. Modifikasi desain pin hook mampu meningkatkan nilai availability pin hook load lugger menjadi 99\% dengan nilai MTBF sebesar 222,33 jam dan nilai MTTR sebesar 1 jam. Penelitian selanjutnya dapat dilakukan dengan implementasi autonomous maintenance untuk meningkatkan keandalan mesin load lugger

\section{DAFTAR PUSTAKA}

Al Rasyid, H. (2018). Peningkatan Nilai Overall Equipment Effectiveness pada Proses Pembuatan Kaca Cermin dengan Metode Fmea. Operations Excellence, 10(1), 47-64. https://publikasi.mercubuana.ac.id/i ndex.php/oe/article/view/3151

Anthony, M. B. (2018). Analisis Penyebab Kerusakan Hot Rooler Table dengan Menggunakan Metode Failure Mode And Effect Analysis (FMEA). Jurnal INTECH Teknik Industri Universitas Serang Raya, 4(1), 1-8. https://doi.org/10.30656/intech.v4i1 .851

Ardyanto, M., and Felecia, F. (2015). Upaya Penurunan Downtime pada Mesin Moulding di PT. X. Jurnal Titra, 3(2), $\begin{array}{llllll}3 & 8 & 3 & - & 3 & 9\end{array}$ http://publication.petra.ac.id/index.p $\mathrm{h} \mathrm{p} / \mathrm{t}$ e $\mathrm{k} n$ i $\mathrm{k}$ industri/article/view/3520

Chen, C.-C. (2013). A developed autonomous preventive maintenance programme using RCA and FMEA. International Journal of Production Research, 51(18), 5404-5412. https://doi.org/10.1080/00207543.2 013.775521

Christi, O. F., and Yuliawati, E. (2020). Peningkatan Efektivitas Mesin TMC Segmen CBE 1160 Melalui Analisis Overall Equipment Effectiveness (OEE)(Studi Kasus: PT. Eta Indonesia). Jurnal Senopati: Sustainability, Ergonomics, Optimization, and Application of Industrial Engineering, 1(2), 64-75. https://ejournal.itats.ac.id/senopati/ article/view/527

Geum, Y., Cho, Y., and Park, Y. (2011). A systematic approach for diagnosing service failure: Service-specific FMEA and grey relational analysis approach. Mathematical and Computer Modelling, 54(11), 3126-3142. https://doi.org/10.1016/j.mcm.2011. 07.042

Hasrul, H., Shofa, M. J., and Winarno, H. (2017). Analisa Kinerja Mesin Roughing Stand dengan Menggunakan Metode Overall Equipment Effectiveness (OEE) dan Failure Mode Effect Analysis (FMEA). Jurnal INTECH Teknik Industri Universitas Serang Raya, 3(2), 55-60. https://doi.org/10.30656/intech.v3i2 .879 
Lo, H.-W., Liou, J. J. H., Huang, C.-N., and Chuang, Y.-C. (2019). A novel failure mode and effect analysis model for machine tool risk analysis. Reliability Engineering \& System Safety, 183, $\begin{array}{lll}1 & 7 & 3\end{array}-\begin{array}{lll}1 & 8 & 3\end{array}$. https://doi.org/10.1016/j.ress.2018. 11.018

Luko, S. N. (2013). Risk Management Principles and Guidelines. Quality Engineering, 25(4), 451-454. https://doi.org/10.1080/08982112.2 013.814508

Mohsen, O., and Fereshteh, N. (2017). An extended VIKOR method based on entropy measure for the failure modes risk assessment - A case study of the geothermal power plant (GPP). Safety Science, 92, 160-172. https://doi.org/https://doi.org/10.1 016/j.ssci.2016.10.006

Parinduri, L., Sibuea, S. R., and Suryadi, W. (2018). Analisa Umur Ekonomis Mesin Perebusan Untuk Perencanaan Replacement (Studi Kasus Di PT. PN IV Kebun Adolina Perbaungan). Buletin Utama Teknik, 14(1), 6-12. https://jurnal.uisu.ac.id/index.php/b ut/article/view/794

Putra, C. D., Syarief, A., and Isworo, H. (2018). Analisa Kegagalan Menggunakan Metode Failure Mode and Effect Analisys (FMEA) Pada Unit Off-Highway Truck 777D. Scientific Journal of Mechanical Engineering Kinematika, 3(1), 33-42. https://doi.org/10.20527/sjmekinem atika.v3i1.4

Reza, D., Supriyadi, S., and Ramayanti, G. (2017). Analisis Kerusakan Mesin Mandrel Tension Rell dengan Metode Failure Mode and Effect Analysis (FMEA). Prosiding Seminar Nasional Riset Terapan| SENASSET, 190-195. $\mathrm{h} \quad \mathrm{t} \quad \mathrm{t} \quad \mathrm{p} \quad \mathrm{s}: / / \mathrm{e}$ - jurnal.lppmunsera.org/index.php/sen asset/article/view/447

Rochmoeljati, R. (2008). Penurunan Jumlah Cacat Produk pada Mesin Insulating dengan Metode Failure Mode Effect Analysis. Jurnal Teknik Industri, 9(1), $\begin{array}{lllll}3 & 7 & - & 4 & 4\end{array}$. https://ejournal.umm.ac.id/index.ph p/industri/article/view/6120

Simeu-Abazi, Z., and Sassine, C. (2001). Maintenance Integration in Manufacturing Systems: From the Modeling Tool to Evaluation. International Journal of Flexible Manufacturing Systems, 13(3), $267-285$. https://doi.org/10.1023/A:10111476 02744

Supriyadi, S, Reza, D., Nalhadi, A., and Nelfiyanti, N. (2019). Mandrel machine scheduling determination based on damage intervals. Journal of Physics: Conference Series, 1175(1), $\begin{array}{llllll}0 & 1 & 2 & 1 & 8 & 8\end{array}$. https://doi.org/10.1088/17426596/1175/1/012188

Supriyadi, S, and Nabilla, M. (2020). Analisa Kegagalan Produk CLIP RI dengan Pendekatan Failure Mode and Effect Analysis (FMEA). Journal of Industrial Engineering, 5(2), 101-109. http://ejournal.president.ac.id/presunivojs/i ndex.php/journalofIndustrialEnginee rin/article/view/1319

Velmurugan, R. S., and Dhingra, T. (2015). Maintenance strategy selection and its impact in maintenance function. International Journal of Operations \& Production Management, 35(12),

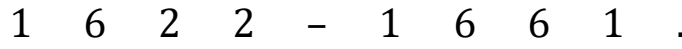
https://doi.org/10.1108/IJOPM-012014-0028

Wang, Y., Cheng, G., Hu, H., and $\mathrm{Wu}, \mathrm{W}$. (2012). Development of a risk-based maintenance strategy using FMEA for 
a continuous catalytic reforming plant. Journal of Loss Prevention in the Process Industries, 25(6),

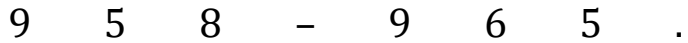
https://doi.org/10.1016/j.jlp.2012.05 .009

Zhou, Y., Xia, J., Zhong, Y., and Pang, J. (2016). An improved FMEA method based on the linguistic weighted geometric operator and fuzzy priority. Quality Engineering, 28(4), 491-498. https://doi.org/10.1080/08982112.2 015.1132320 